\title{
Cómo dialogar en la planificación local del patrimonio cultural. Tres experiencias en la isla de Tenerife
}

Carlos Antonio Benítez Méndez | antropólogo social y consultor técnico independiente

URL de la contribución <www.iaph.es/revistaph/index.php/revistaph/article/view/4615>

\section{RESUMEN}

¿Cómo podrían converger el conocimiento experto, la gestión técnica y política, y el saber de las personas y los colectivos culturales en la planificación local del patrimonio cultural? ¿Qué metodologías e instrumentos podríamos usar para avanzar hacia un modelo de participación activa en las decisiones públicas, es decir, de gobernanza participativa del patrimonio cultural? Este artículo intentará aportar un conjunto de experiencias de planificación en la isla de Tenerife basadas en la creación de espacios colectivos de diálogo como un instrumento eficaz para la reflexión, el diagnóstico y la toma de decisiones sobre el patrimonio cultural municipal incorporando la pluralidad de actores y perspectivas sobre el mismo para alcanzar una visión común. El protagonismo de las comunidades en la gestión de su patrimonio cultural ha sido, de hecho, reconocido por organizaciones como la UNESCO o la Unión Europea, mientras que el "giro dialógico" (Aubert et ál. 2013) del tiempo actual está desplazando las relaciones autoritarias por otras sustentadas en el diálogo y en la búsqueda de consenso en todos los órdenes de la sociedad, como en la propia forma de generar conocimiento o de tomar decisiones en el ámbito público. Metodologías participativas como las del World Café nos han ofrecido, en este sentido, una oportunidad para facilitar el diálogo sobre el patrimonio cultural en un contexto de igualdad entre los distintos actores de la comunidad en tres municipios de la isla de Tenerife como son Tegueste, Candelaria y Santiago del Teide.

\section{Palabras clave}

Diálogo | Gobernanza | Metodología | Participación ciudadana | Patrimonio cultural | Planificación estratégica | Tenerife | 


\section{INTRODUCCIÓN: TODOS SOMOS RESPONSABLES Y PROTAGONISTAS}

Todas las citas se corresponden con extractos de entrevistas realizadas durante la fase de diagnóstico de los diferentes proyectos referidos en este artículo.

\section{2}

Así lo expresa, por ejemplo, la definición de patrimonio cultural inmaterial de la UNESCO: "los usos, representaciones, expresiones, conocimientos y técnicas [...] que las comunidades, los grupos y en algunos casos los individuos reconozcan como parte integrante de su patrimonio cultural" (UNESCO 2003).
Ideas reflejadas en papel Kraft durante el taller participativo para la elaboración del diagnóstico y plan de gestión del patrimonio cultural de Tegueste (Tenerife), 2018
"Hay que contar con la gente de La Barranquera porque son ellos los que van a proteger los yacimientos. Hay que contar con la gente, si no, no sirve de nada. Porque tampoco tiene sentido. ¿Para qué vas a hacer una cosa en la que la gente no participa? La gente, si siente que es suyo, da un montón y salen las cosas, seguro. Si lo siente suyo, lo protege, lo cuida, lo desarrolla mucho más." (arqueóloga ${ }^{1}$ ).

"Yo creo que sí, que la gente en general se siente identificada con lo que se expone a través de la exposición. He intentado facilitar tanto en la redacción del proyecto, como en la ejecución del proyecto, como ahora ya en la dinamización del proyecto, que los distintos colectivos de alguna manera participen. Al final es buscar que la gente se encuentre en el centro de interpretación, que sea su punto de encuentro, pero siempre en clave patrimonial." (gestora cultural).

Del mismo modo que las citadas especialistas en gestión del patrimonio cultural, organizaciones como la Unión Europea o la UNESCO llevan algún tiempo apelando al protagonismo que las comunidades locales deberían tener en la gestión de su patrimonio cultural, entendido este, aunque sea solo en parte, como un bien común y un recurso estratégico con el que aquellas cuentan; un patrimonio que, para serlo, además debe ser "reconocido"2 como tal por dichas comunidades. Es precisamente el valor que los colectivos ciudadanos y culturales, los especialistas, o los gestores técnicos y políticos concedemos al patrimonio, lo que constituye la "fuerza

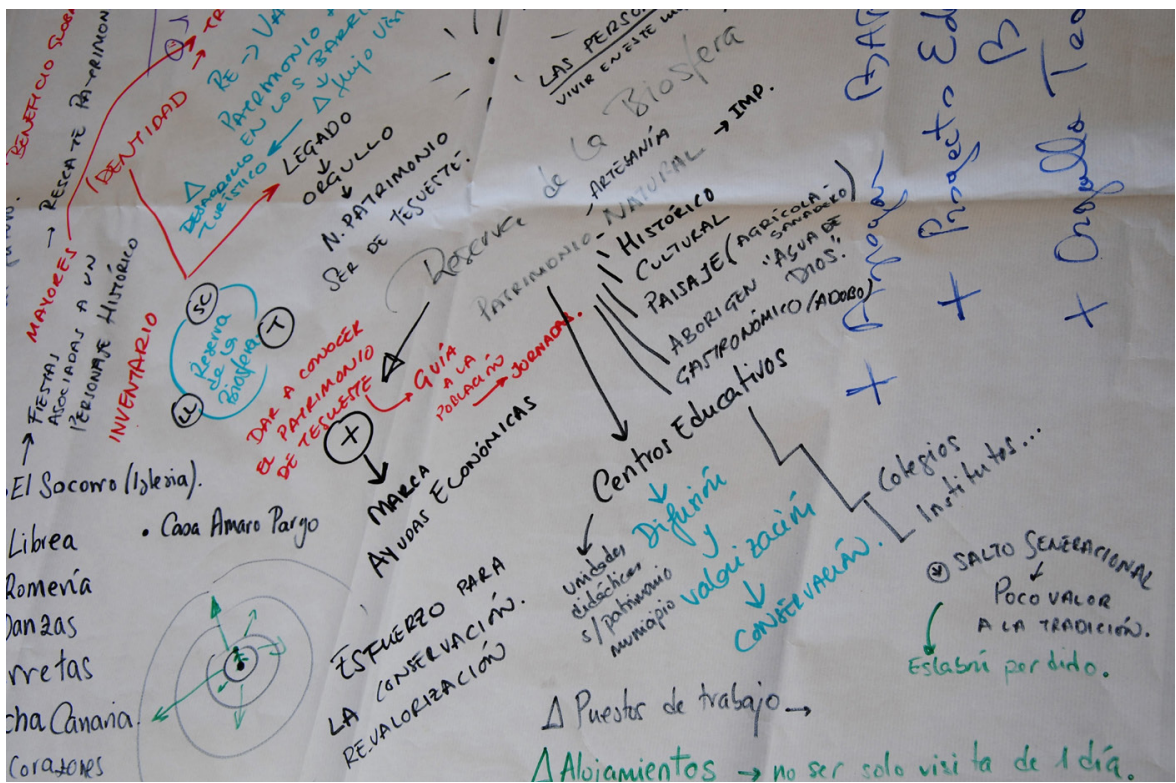


motriz" que nos conduce a participar en su protección, valorización o gestión (Sani 2016).

Tomar en consideración estas premisas como punto de partida, es decir, el patrimonio como construcción social ${ }^{3}$, es de importancia estratégica en la promoción del diálogo como metodología de planificación, pues es a través de la creación de espacios municipales de diálogo como la diversidad de voces respecto al patrimonio cultural -incluyendo las voces en conflictopuede ser visibilizada, reconocida y encauzada hacia el interés común. De hecho, el patrimonio, muy lejos de componer un placentero campo para el esparcimiento, "pone de relieve las contradicciones y tensiones inherentes a la sociedad desigual y compleja que habitamos" (Quintero Morón y SánchezCarretero 2017, 55).

Asumir el carácter conflictual de los procesos de patrimonialización nos brinda, al contrario de lo que podría suponerse, el pretexto para el reconocimiento mutuo de todas las partes, para la reflexión colectiva, y para forjar consensos en torno a la gestión pública del patrimonio cultural local integrando en ella la multiplicidad de actores, perspectivas, posiciones e intereses que puedan llegar a concurrir. Las Conclusiones del Consejo sobre la gobernanza participativa del patrimonio cultural (Consejo de Europa 2014) abogan, en este sentido, "por la participación activa de las partes interesadas pertinentes en el marco de la actuación pública -es decir, las autoridades y los organismos públicos, los agentes privados, las organizaciones de la sociedad civil, las ONG, el sector del voluntariado y las personas interesadas- en la toma de decisiones, la planificación, la puesta en práctica, la

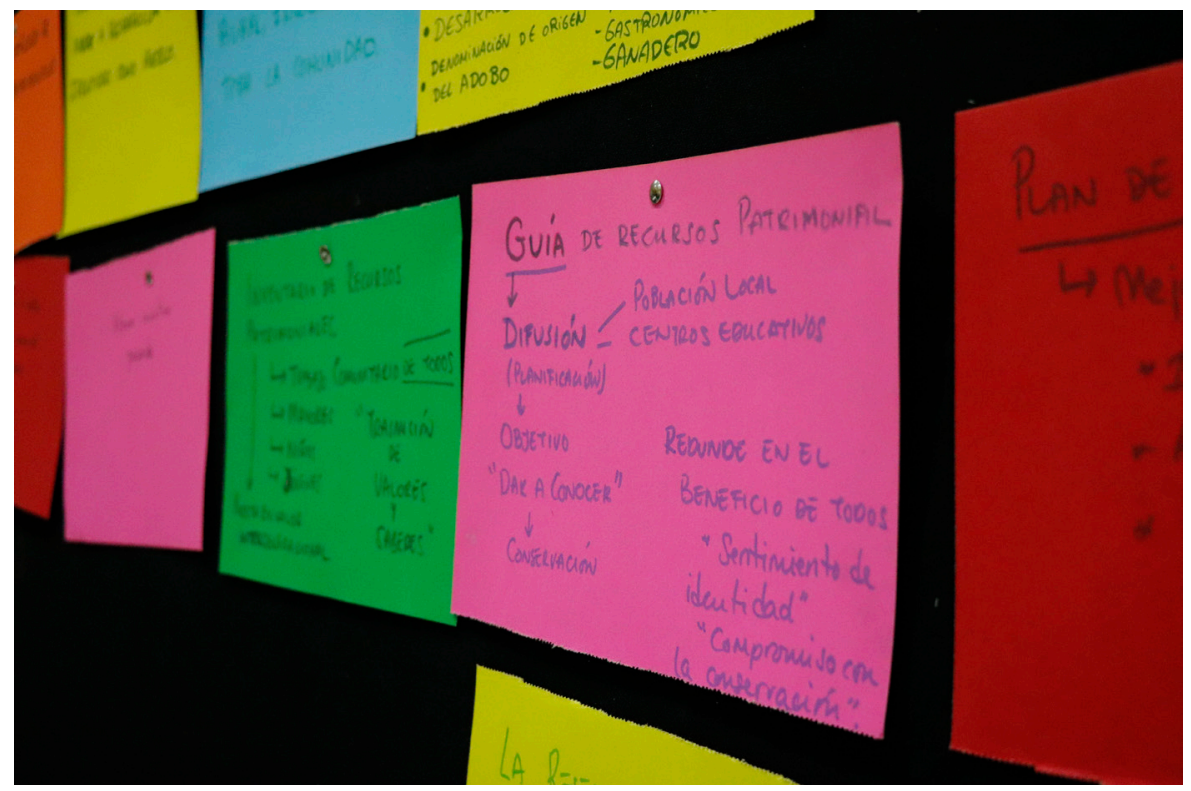

3

Un punto de partida que se suele dar por hecho en disciplinas como la antropología (Sánchez-Carretero 2012, 197).

Resultados del taller participativo para la elaboración del diagnóstico y plan de gestión del patrimonio cultural de Tegueste (2018) 


\section{4}

El Convenio Marco del Consejo de Europa sobre el valor del patrimonio cultural para la sociedad (Convenio de Faro 2005) ya se comprometía con la responsabilidad y la participación de todas las partes en la gestión del patrimonio cultural (artículos 11 y 12).

\section{5}

La Ley 10/2015, de 26 de mayo, para la salvaguardia del Patrimonio Cultural Inmaterial, recoge entre los "Principios generales de las actuaciones de salvaguardia" (artículo 3) tanto el protagonismo como la participación de las comunidades portadoras del patrimonio cultural inmaterial en la recreación, transmisión y difusión del patrimonio cultural inmaterial. Por su parte, el Plan Nacional de Salvaguardia del $\mathrm{PCl}$ (2011) dio cumplimiento a la implementación de la Convención para la Salvaguardia del Patrimonio Cultural Inmaterial de la Unesco (UNESCO 2003), ratificada por España en 2006.

\section{6}

Los planes de gestión municipal han sido desarrollados por Cultania, empresa especializada en la gestión del patrimonio cultural en el ámbito de las islas Canarias, y en los que el autor de este artículo ha participado como parte del equipo en las diferentes fases de planificación. Los planes estuvieron basados en el marco de gestión propuesto por la UNESCO, en el que se consideran tres elementos (marco jurídico, marco institucional y recursos), tres procesos (planificación, ejecución y monitoreo) y tres resultados (productos, resultados y mejoras) (UNESCO 2014).

7

Siguiendo a Sani, podemos entender por go bernanza participativa "un proceso mediante el cual se cede parte del poder y se adoptan nuevos modelos de gestión, de forma que la responsabilidad pasa a ser compartida y las decisiones son tomadas, no tanto por individuos, como por comunidades" (Sani 2016). supervisión y la evaluación de las políticas y los programas en materia de patrimonio cultural para aumentar la responsabilidad y la transparencia de las inversiones de recursos públicos y para generar confianza pública en las decisiones políticas"4.

En el contexto español, al menos la Ley para la salvaguardia del Patrimonio Cultural Inmaterial (Ley 10/2015) y el Plan Nacional de Salvaguardia del Patrimonio Cultural Inmaterial, de 2011, (Ministerio de Educación, Cultura y Deporte 2015), también reconocen ${ }^{5}$ el ineludible protagonismo de las comunidades en la toma de decisiones sobre su patrimonio cultural inmaterial. Pero, ¿cómo podría activarse ese protagonismo en la práctica de los escenarios locales?, ¿cómo pueden darse la mano en condiciones de horizontalidad y corresponsabilidad el conocimiento y la gestión tradicionalmente expertos, la gestión política (que no es necesariamente experta) y el conocimiento cultural tanto de las personas y colectivos que protegen, recrean, y/o transmiten el patrimonio cultural como de cualquier vecino o vecina, asociación, colectivo, etc., con mayor o menor preocupación por el mismo? ¿Qué metodologías, en definitiva, podemos poner en marcha para transitar de un modelo tendencialmente formulista a otro de participación efectiva en la planificación municipal del patrimonio cultural? Desde luego esto no es nada sencillo, pero nuestra experiencia en la aplicación de metodologías centradas en las personas y en el diálogo como parte esencial de los procesos de elaboración de diagnósticos y planes de gestión municipales en la isla de Tenerife $^{6}$ ha sido tan gratificante e inspiradora para las personas participantes como estratégica para la construcción colectiva de iniciativas que luego hemos traducido a ejes de actuación con sus correspondientes acciones específicas. Los ejes no solo han procurado ser la consecuencia de una "visión común", sino que, en algunos casos, han ido destinados a proponer mecanismos estables de gobernanza participativa ${ }^{7}$ del patrimonio cultural (como mesas o foros de participación ciudadana) que pudiesen dar profundidad y continuidad en el tiempo a esa visión común.

En la literatura científica son recurrentes los modelos que gradúan en diferentes niveles la participación ciudadana en las decisiones públicas. Todos y todas podemos tener en la mente la clásica escalera de la participación de Arnstein (1969), que progresa desde un conjunto de peldaños en los que no habría participación hasta alcanzar aquellos en los que la ciudadanía tomaría parte en las decisiones públicas. Son contribuciones igualmente interesantes las de Nina Simon (2000) clasificando las prácticas participativas en el sector cultural en cuatro categorías (proyectos contributivos, proyectos colaborativos, proyectos co-creativos y proyectos alojados), o los cuatro niveles de inclusividad en las decisiones públicas de Sclavi (2010), desde el expertismo puro (nivel 0), pasando por el expertismo impuro (nivel 1), la comunidad indagante (nivel 2), hasta que el aprendizaje recíproco y colectivo entre protagonistas, así como la escucha activa y la creatividad 
del nivel anterior se afianzan en la práctica cotidiana de la administración pública (nivel 3).

La metodología que compartimos en este artículo ha querido facilitar a las comunidades, a través de la experiencia vivida por políticos, técnicos y ciudadanía con su aplicación, un medio colectivo, creativo y eficaz para repensar la gestión municipal de un bien común como es el patrimonio cultural, "haciendo ver" que es posible avanzar hacia los niveles más próximos a la participación "real" simplemente con permitir que la comunidad se encuentre para pensar y decidir juntos.

Qué es "la comunidad" en relación con el patrimonio cultural bien merece una profunda reflexión que no podemos acometer en este artículo. En el diseño de nuestros procesos de planificación, hemos considerado que, idealmente, la comunidad la compone no solo las personas o los colectivos portadores del patrimonio cultural local, sino también los gestores políticos, los técnicos públicos y privados, las asociaciones vecinales, los colectivos de mayores, jóvenes y mujeres, los centros educativos, la parroquia, las asociaciones ecologistas o de defensa del patrimonio, el mercadillo del agricultor, las asociaciones profesionales y de empresarios, etc.; es decir, siguiendo a Marchioni (1999), las administraciones, los servicios públicos y privados, y la población y sus organizaciones, que vendrían a representar los tres protagonistas del proceso comunitario. Las divisorias internas de la comunidad tienden, por lo demás, a ser vaporosas, pues no es inaudito encontrar que el concejal de obras y servicios es al mismo tiempo "portador" de una destacada manifestación cultural, que la "experta" gestora del centro de interpretación es heredera y difusora de una antigua artesanía, o que la presidenta de la reivindicativa asociación vecinal es la mayor "autoridad" en folclore local. Se trata, por consiguiente, de equilibrar las relaciones de poder, de que todos y todas puedan aportar desde su ámbito vivencial y/o profesional, y de que "se reconozcan" como parte necesaria en la gestión pública del patrimonio cultural.

Hasta cierto punto podemos afirmar, igualmente, que la comunidad se va haciendo a sí misma durante el proceso participativo, pues el mapa inicial de actores siempre acabará derivando en otro más amplio y complejo. Son los propios protagonistas, empleando la técnica de la bola de nieve, los que señalarán con quién "se debe" contar (y con quién no), hasta que conseguimos configurar una masa crítica suficiente para comenzar el proceso de planificación con ciertas garantías de representación. El mapeo de actores (a través de encuentros iniciales, de entrevistas, de la observación, o de la consulta de bases de datos, páginas web, RRSS, etc.) contribuirá a identificar y analizar la red local de relaciones ${ }^{8}$ no solo con respecto al ámbito patrimonial, sino con respecto a la estructura social de la comunidad en su conjunto en todos los ámbitos de interés (político, económico,
El análisis de redes sociales, elaborando instrumentos como el sociograma, resulta de gran ayuda para visualizar los vínculos existentes en el campo del patrimonio municipal: "Para impulsar una participación transformadora [...] resulta fundamental el conocimiento de las relaciones entre los actores, la estructura de la red que configuran, y el funcionamiento de la misma" (Garrido García 2001, 50). Nos permitirá, inclusive, determinar con qué apoyos y oposiciones contamos para desarrollar la planificación participativa: "Una muestra de las posiciones fundamentales que nos interesa conocer, en cuanto a sus motivaciones de cara a los objetivos que perseguimos, es algo muy importante para saber conjugar qué fuerzas y con qué sentidos se están construyendo. Nos interesan los motivos de los que apoyan el proyecto, tanto como los que están en contra" (Martín Gutiérrez y Villasante 2007, 131). 


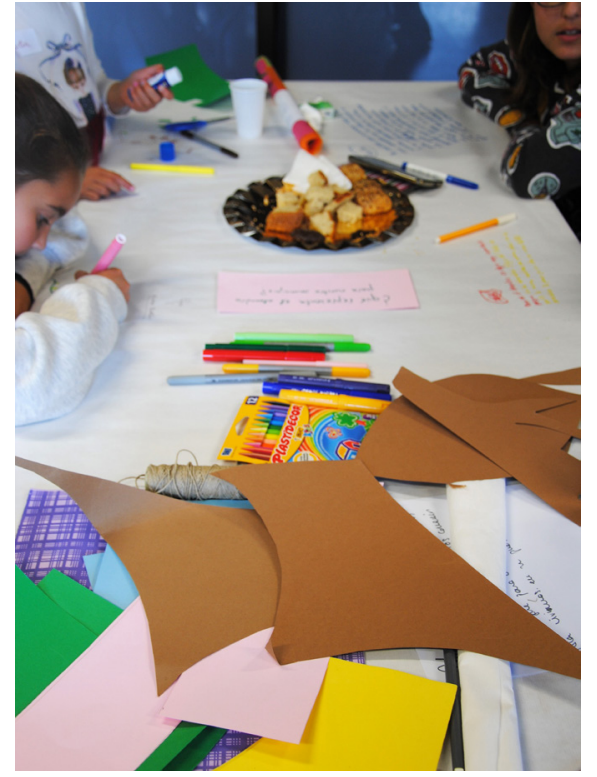

Niños participando en el Taller participativo para la protección y la puesta en valor de la cultura del almendro de Santiago del Teide (2018) 9

Parque Nacional del Teide, Parque Natural de La Corona Forestal, Parque Rural de Teno Reserva Natural Especial del Chinyero y Monumento Natural del Teide. social, cultural, etc.), y de cuya estructura el patrimonio cultural no puede ser aislado.

\section{¿QUIÉN SE ESTÁ OCUPANDO DE NUESTRO PATRIMONIO?}

Los tres municipios tinerfeños en los que recientemente hemos diseñado planes de gestión comparten ciertas características, pero en general constituyen tres contextos diversos en cuanto a condiciones geográficas, características demográficas y actividades productivas en una isla preferentemente orientada al turismo de descanso y de ocio:

Candelaria es una localidad costera que ha soportado una fuerte transformación urbanística y poblacional, convirtiéndose en ciudad dormitorio del área metropolitana de Tenerife (de la que dista 18 kilómetros), y cuyo símbolo, la Virgen de Candelaria (patrona de Canarias), la convierte en lugar de peregrinaje y, gracias también a un clima benigno durante todo el año, en destino turístico.

Santiago del Teide, una pequeña localidad de montaña (a 930 metros altitud), es conocida por su vinculación al cultivo del almendro, habiendo florecido, a pesar de su actual estado de semiabandono, una pequeña industria turística en torno al mismo (rutas guiadas, senderismo, venta de productos artesanales, etc.), así como por estar el $66,5 \%$ del territorio municipal incluido dentro de varios espacios naturales protegidos ${ }^{9}$. En la zona costera (a 11 kilómetros) se ha desarrollado uno de los principales enclaves turísticos de la isla (Puerto de Santiago y Acantilados de Los Gigantes), originándose un significativo contraste poblacional y productivo entre las zonas altas y la costa.

Tegueste es un municipio vitivinícola que ha conservado un atractivo paisaje rural y agrario, siendo uno de los pocos municipios de la isla, junto con Vilaflor y El Tanque, sin salida al mar, el único casco urbano incluido en la Reserva de la Biosfera Macizo de Anaga, y probablemente el primero de la isla en contar con un centro de interpretación y un parque arqueológico dedicado al mundo guanche. Autodenominado como "cuna de las tradiciones", destacan la Librea y la Romería de San Marcos Evangelista. También ha experimentado un importante crecimiento poblacional debido a su cercanía al área metropolitana, erigiéndose como ciudad dormitorio con urbanizaciones acomodadas.

La situación que nos encontramos en todos los municipios para emprender planes de gestión del patrimonio cultural es, cuando menos, nebulosa. En ellos el patrimonio cultural no tiene reconocido un espacio político ni técnico propio (como una concejalía con competencias delegadas o una oficina técnica), estando "troceada" su gestión, tal y como identificaron los diagnósti- 


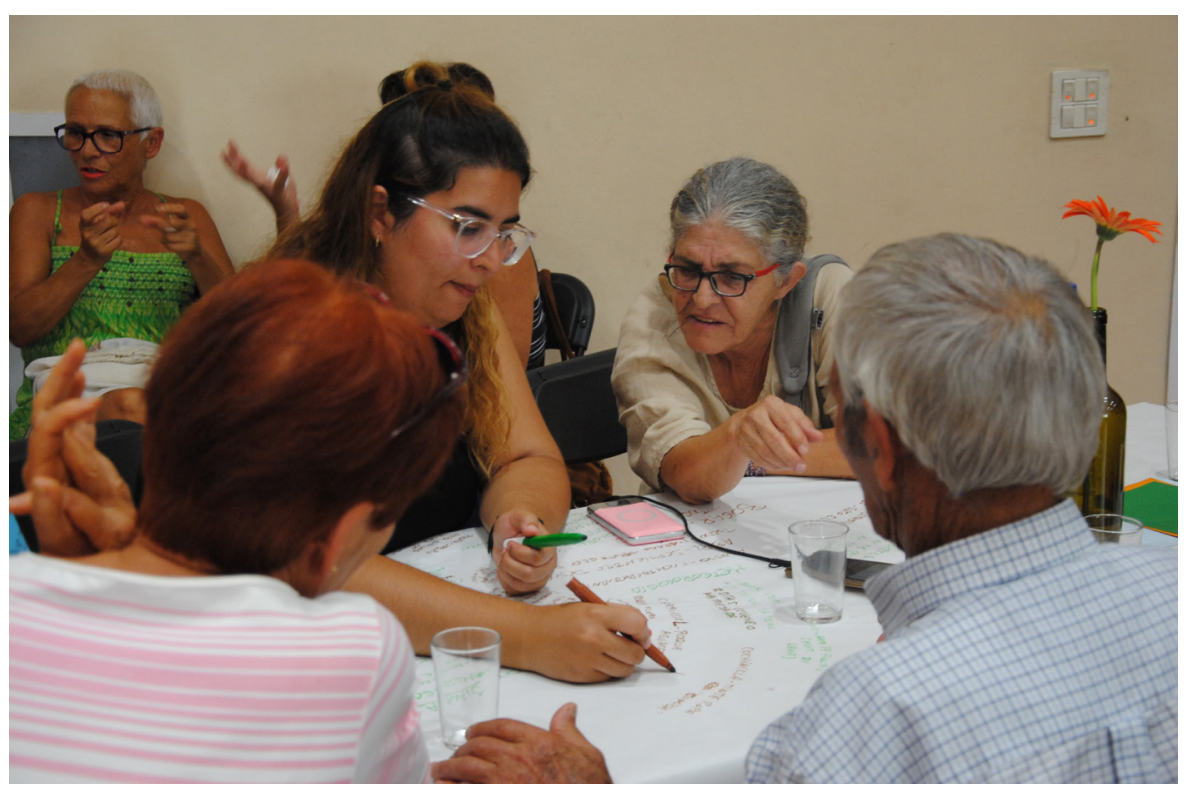

$\cos _{\text {previos }}{ }^{10}$, en áreas como Identidad Canaria, Cultura, Turismo, Fiestas, Medioambiente, Desarrollo Local, e incluso Participación Ciudadana, cada cual abordando el patrimonio cultural desde su particular foco de interés y con escasa o nula colaboración entre áreas para impulsar proyectos conjuntos.

"Las competencias no están claras, ese es uno de los problemas del patrimonio en este municipio. Ha sido así durante muchos años, esa es una de las causas del abandono y deterioro. Se hace uso del patrimonio, pero no se ha velado por su conservación ni recuperación" (técnico municipal).

El patrimonio cultural, por tanto, estaría invisibilizado institucionalmente, y derivado de ello tampoco ha habido políticas integrales de gestión patrimonial, aunque a él se alude recurrentemente en el discurso político y en la simbología institucional. Patrimonio e identidad -podemos agregar "y tradición"- tienden a confluir y a confundirse, mostrándonos el trasfondo político que puede adquirir el patrimonio.

"No sé si existe como tal, pero quien se suele encargar de este tipo de cuestiones es Identidad, que va un poco relacionado."

"Hay una concejalía que tiene un vínculo con lo que es la parte de las tradiciones, y en Fiestas también existe una parte que también se vincula con la cultura, el patrimonio de forma genérica. Luego una cosa muy distinta es que el Ayuntamiento haya luego tenido medios para hacer muchas cosas. Nunca ha habido una concejalía que se dedique intensa, exclusiva y abiertamente a trabajar el patrimonio."
Taller participativo para el Inventario del Patrimonio Cultural Inmaterial Marítimo-Pesquero de la Reserva de la Biosfera de Anaga (Punta del Hidalgo, La Laguna, 2019)

10

Diagnósticos que también han sido autodiagnósticos en la medida en que fueron el resultado de la aportación de colectivos ciudadanos, técnicos municipales y gestores políticos a través del empleo de técnicas como la entrevista individual y grupal, el transecto, el árbol de problemas, o el análisis DAFO. 
Tal y como lo expresaron los anteriores técnicos municipales, esta es una particularidad que encontramos en dos de los contextos locales, es decir, la ausencia de áreas de patrimonio histórico o cultural pero la presencia de otras como identidad canaria, que asumen la gestión política de las manifestaciones culturales tradicionales, o del denominado patrimonio cultural inmaterial, toda vez que respecto a la gestión del patrimonio material (incluyendo el patrimonio arqueológico), la nebulosa se transforma en un nubarrón. Así lo advirtieron otros técnicos municipales:

"En la práctica, la ley de patrimonio histórico de Canarias no se cumple. No está hecho el plan de protección del casco histórico, no hay inventarios hechos, el catálogo arquitectónico está mal hecho, no hay nada del patrimonio etnográfico."

"Muchas de las casas tienen los cimientos adentrados en la ladera, con escaleras en la parte trasera que conducen a las partes más accesibles del barranco y que llevan a las cuevas que han sido almacenes de distinta naturaleza. Basura, vertidos, pozos negros, depósitos de aguas residuales. Debajo de todo eso están los yacimientos arqueológicos."

La tendencia general hacia la desprotección de los conjuntos históricos, de los yacimientos arqueológicos, o de los elementos etnográficos, ha sido -siempre como hipótesis- un efecto derivado de estos específicos procesos locales de patrimonialización que han priorizado determinadas manifestaciones culturales como parte del proceso de construcción identitaria de los canarios iniciado en los años setenta del pasado siglo, siendo el recurso al pasado un aspecto crucial del mismo (Galván 2002, 173).

Pero no solo identidad incluyendo memorias y excluyendo otras: en un territorio abocado al turismo como el canario, la gestión turística -y junto a ella la indisociable gestión urbanística- ha podido desplazar, y hasta suplantar, la propiamente patrimonial, subordinando el patrimonio al mercado y convirtiéndolo en variable dependiente del turismo (HernándezRamírez y Quintero Morón 2019, 77). La actividad turística acostumbra a usar como punta de lanza singulares elementos del territorio, la historia y la cultura (paisajes naturales y agrarios, clima, pasado aborigen, folclore, fiestas, etc.) contribuyendo, de este modo, al proceso de valorización del patrimonio. Debajo de todo ello parece imperar, sin embargo, una suerte de anomia patrimonial. Es el caso, por ejemplo, del patrimonio cultural vinculado al cultivo del almendro en el municipio de Santiago del Teide, cuyo "exitoso" programa anual de rutas (incluidas en la denominada Campaña Almendros en Flor) ha provocado una turistificación sin llevar aparejado un plan de salvaguarda de una actividad y un patrimonio agrarios en declive debido a la creciente desagrarización de la isla de Tenerife (Godenau y Suárez 2009). 
El proyecto de protección y puesta en valor de la cultura del almendro de Santiago del Teide que realizamos durante el año 2018 pretendió hacer partícipe a la comunidad tanto en el diagnóstico como en la exploración de iniciativas para una actividad en franco retroceso que trascendiese el efímero atractivo turístico de la floración del almendro (enero-febrero) para incluir todo el conjunto de valores inherentes al agroecosistema (ecológicos, agronómicos, culturales, económicos, etc.), y que llegue a convertirse en un factor de desarrollo sostenible en beneficio de la población local actual y futura. El proceso de diagnóstico mostró, no obstante, que los vecinos, y en particular los propietarios de almendros, abrigaban un sentimiento de abandono por parte de la gestión municipal, la cual estaría priorizando el desarrollo de la costa en detrimento de las zonas rurales del municipio. El diagnóstico reveló, entre otras muchas cosas, la escasa rentabilidad del cultivo y la ausencia de relevo generacional, el desconocimiento de la titularidad de las tierras y de los árboles, el estado de abandono de los almendros, la introducción de almendras foráneas, la sequía, los robos, etc., así como la situación percibida de invasión del territorio ante el "rebaño de personas" -así lo expresaron los propios vecinos- que acuden cada año a las rutas, produciéndose roturas de ramas y de flores.

A la ausencia de gestión técnica del patrimonio cultural municipal debemos añadir que las personas no han sido capacitadas ni estimuladas para participar en la definición de las políticas públicas que les afectan cotidianamente, si bien se han venido desarrollado reglamentos de participación ciudadana, mesas de participación vecinal y sectorial, o presupuestos participativos que, con desigual grado de aplicación en cada municipio, podrían comenzar a inducir una acción colectiva en torno al patrimonio cultural si los modelos participativos institucionales se orientan hacia la corresponsabilidad, la codecisión y la cogestión de este bien común. Precisamente, en estos incipientes mecanismos participativos municipales (los tres municipios cuentan con alguno) nos apoyamos para diseñar con la comunidad la planificación del patrimonio cultural.

"La gente no participa", suelen decir con frecuencia los responsables políticos y gestores técnicos. En realidad, la gente sí participa continuamente en su vida diaria en muchas cosas, y también en su patrimonio cultural, protegiéndolo, recreándolo ${ }^{11}$, transmitiéndolo ${ }^{12}$, e incluso investigando sobre él; pero no se le han puesto los medios para hacerlo en la toma de decisiones referidas al patrimonio cultural como bien público, teniendo en cuenta, además, que para estos municipios su patrimonio cultural, visto aquí simplemente como un recurso, podría llegar a ser estratégico como alternativa sostenible de desarrollo, de tal modo que el patrimonio cultural pasaría a formar parte de una estrategia territorial más amplia ${ }^{13}$ en la que normalmente tampoco hay planificación a largo plazo ni mecanismos que garanticen la participación ciudadana en el proceso decisional.
11

La Librea de Tegueste suele congregar cada cuatro años a unos seiscientos figurantes (la mayoría vecinos y vecinas del municipio), mientras que la Ceremonia Guanche de Candelaria cita anualmente en torno a cien participantes pertenecientes al Colectivo de los Guanches de Candelaria.

12

Los colectivos culturales que participaron en la fase de diagnóstico en los tres procesos advirtieron un distanciamiento de la juventud respecto de la cultura tradicional, una contingencia que suele ser vivida, si no como un drama, sí como una amenaza para la continuidad de las manifestaciones culturales locales, o, por emplear la terminología especializada, para la salvaguardia del patrimonio cultural inmaterial.

13

En esa estrategia territorial más amplia, la salvaguardia del patrimonio rural y agrario puede contribuir, por ejemplo, a otro ámbito de acción pública como es el fomento de la soberanía alimentaria a través del mantenimiento de la actividad agraria. Actualmente (2019-2020) estamos llevando a cabo diversos proyectos para el fomento de la soberanía alimentaria en los municipios tinerfeños de La Orotava y San Cristóbal de La Laguna en el marco de la adhesión de los mismos al Pacto Estatal por la Soberanía Alimentaria, la Educación Ambiental y la Sostenibilidad del Territorio (Pacto Intervegas). 


\begin{tabular}{|c|c|c|c|c|c|c|}
\hline & Proyecto & $\begin{array}{l}\text { Localización/ } \\
\text { Demografía* }\end{array}$ & $\begin{array}{l}\text { Referentes } \\
\text { patrimoniales }\end{array}$ & $\begin{array}{l}\text { Concejalía, } \\
\text { área u oficina } \\
\text { técnica de PC }\end{array}$ & $\begin{array}{l}\text { Concejalía o } \\
\text { área de identi- } \\
\text { dad canaria }\end{array}$ & $\begin{array}{l}\text { Concejalía o área } \\
\text { de Participación } \\
\text { Ciudadana }\end{array}$ \\
\hline Candelaria & $\begin{array}{l}\text { Diagnóstico y plan de } \\
\text { gestión del patrimonio } \\
\text { cultural (2017) }\end{array}$ & $\begin{array}{l}\text { SE de Tenerife } \\
27.149 \text { hab. } \\
\text { Casco (12.795 hab.) }\end{array}$ & $\begin{array}{l}\text { Virgen y Basílica } \\
\text { de Candelaria } \\
\text { (BIC) } \\
\text { Camino Viejo de } \\
\text { Candelaria (BIC) } \\
\text { Ceremonia } \\
\text { guanche }\end{array}$ & No dispone & $\begin{array}{l}\text { Identidad } \\
\text { Canaria y } \\
\text { Fomento de las } \\
\text { Tradiciones }\end{array}$ & $\begin{array}{l}\text { Sí (con mesas } \\
\text { vecinales) }\end{array}$ \\
\hline Tegueste & $\begin{array}{l}\text { Diagnóstico y plan de } \\
\text { gestión del patrimonio } \\
\text { cultural (2018) }\end{array}$ & $\begin{array}{l}\text { NE de Tenerife } \\
11.108 \text { hab. } \\
\text { Casco ( } 4.166 \text { hab.) }\end{array}$ & $\begin{array}{l}\text { Librea (BIC) } \\
\text { Romería de San } \\
\text { Marcos } \\
\text { Parque Rural de } \\
\text { Anaga (Reserva } \\
\text { de la Biosfera) } \\
\text { Zona arqueológica } \\
\text { Barranco Agua de } \\
\text { Dios (BIC) }\end{array}$ & No dispone & $\begin{array}{l}\text { Fomento de } \\
\text { las Tradiciones } \\
\text { Culturales e } \\
\text { Históricas }^{\star \star}\end{array}$ & $\begin{array}{l}\text { Sí (con regla- } \\
\text { mento y mesas } \\
\text { vecinales) }\end{array}$ \\
\hline $\begin{array}{l}\text { Santiago } \\
\text { del Teide }\end{array}$ & $\begin{array}{l}\text { Proceso participativo } \\
\text { para la protección y la } \\
\text { puesta en valor de la } \\
\text { cultura del almendro de } \\
\text { Santiago del Teide (2018) }\end{array}$ & $\begin{array}{l}\text { SO de Tenerife } \\
10.576 \text { hab. } \\
\text { Casco (425 hab.) }\end{array}$ & $\begin{array}{l}\text { Espacios naturales } \\
\text { protegidos }\end{array}$ & No dispone & No dispone & $\begin{array}{l}\text { Sí (con } \\
\text { reglamento) }\end{array}$ \\
\hline
\end{tabular}

Principales características de los tres municipios. * Fuente: ISTAC, 2017. **Según Decreto de Alcaldía, con "atribuciones relativas a la conservación, divulgación y protección de las tradiciones propias de la identidad de Tegueste para garantizar su conservación y conocimiento"

Entre dichos escenarios podemos incluir también la elaboración del Inventario participativo del Patrimonio Cultural Inmaterial Marítimo-Pesquero de la Reserva de la Biosfera de Anaga (2019), englobando los municipios de Santa Cruz de Tenerife, La Laguna y Tegueste. En los talleres para construir una visión común respecto a los elementos patrimoniales sentidos y/o percibidos como significativos para incluirlos en un inventario, participaron pescadores en activo y retirados, surfistas, asociaciones vecinales y de mayores, agrupaciones folclóricas, movimientos ecologistas, o especialistas de diverso tipo (académicos, técnicos, etc.).

\section{DE LA VELADA NEGOCIACIÓN DEL PASADO AL DIÁLOGO ABIERTO POR EL FUTURO}

Los anteriores son, de manera muy simplificada, algunos de los escenarios en los que hemos tratado de abordar la planificación del patrimonio cultural ${ }^{14}$. En algunos casos la planificación ha sido el fruto de un proceso que podemos considerar participativo (Tegueste y Santiago del Teide), por cuanto ha procurado involucrar a la comunidad tanto en la definición de los problemas como en la búsqueda de soluciones a través de un proceso de investigación y acción. Esta metodología, que sensibiliza, moviliza, visibiliza actores, posiciones y relaciones, y que pretende la reflexión y la acción colectiva en contextos sociales que son siempre sumamente complejos, requiere de tiempo y compromiso político -y ciudadano- que generalmente se dan de forma precaria, lo que podría entenderse como una tercera problemática inicial. No 
obstante, sí que concurre una tercera tendencia de alcance global y que es la que nos compromete a proponer un modo consecuente de actuar sobre el patrimonio cultural en vez de seguir haciéndolo desde un enfoque exclusivamente tecnocrático que no parece estar funcionado, entre otras razones porque tal enfoque ni siquiera acostumbra a estar presente en la gestión municipal del patrimonio cultural.

Ideas como diálogo, consenso, participación, pluralidad, colaboración, y seguramente muchas otras, no están por casualidad en el lenguaje de las organizaciones y las administraciones que guían y regulan el patrimonio cultural, pues la reflexividad de las prácticas sociales propias de la modernidad tardía (Giddens 2015) o de la modernización reflexiva (Beck, Giddens y Lash 1997) también está permeando la gestión del patrimonio cultural, que puede ser considerado, como fenómeno moderno que es, "una forma de modernización y superación de la tradición, por cuanto comporta reflexividad y conciencia de riesgo" (Ariño 2007, 72). Si como supone Giddens "la modernidad está totalmente constituida por la aplicación del conocimiento reflexivo" $(2015,47)$, entonces insistir en modelos determinísticos que ya saben a qué resultados quieren llegar y que por ello no es necesaria la intervención del lego sería como nadar a contracorriente de los tiempos de una nueva modernidad cuyos sujetos poseen la "capacidad de reflexionar sobre sus condiciones sociales y de cambiarlas" (Beck, Giddens y Lash 1997, 209).

Creemos que una manera de canalizar sistemática y estructuradamente la multiplicidad de modos de sentir, pensar y actuar sobre el patrimonio cultural hacia un proyecto común de cambio (como puede ser un plan de gestión que intenta construir un futuro potencial) es a través de la creación de espacios de diálogo ${ }^{15}$, que no es -al menos para el caso que nos ocupa- un modo educado de conversar, sino de equilibrar las relaciones de poder, de trascender la racionalidad instrumental y el soliloquio a puerta cerrada del gestor técnico o político, y, si fuera aun el caso, de dejar igualmente atrás el sistema de debate (de suma cero: "yo gano, tú pierdes") como estrategia comunicativa en el proceso de toma decisiones (Sclavi 2010; Aguilar y Buraschi 2017). El conocimiento y la acción sobre el patrimonio cultural (tanto el que ha sido institucionalizado como el que ha quedado al margen de los procesos de valorización institucional) deja de ser, pues, algo exclusivo de especialistas, moviéndonos a adoptar sistemas de gestión que desmonopolicen el conocimiento experto (Beck, Giddens y Lash 1997, 46) para abrirnos conscientemente a la pluralidad interpretativa del patrimonio cultural (González Alcantud 2003), como la -interpretación- que hacen los vecinos y las vecinas del barrio al reivindicar la "silenciada" figura del pirata-corsario benefactor de los pobres y de la parroquia, como la del historiador aficionado que afirma que la vieja creencia popular es un bulo que no refleja la verdad histórica de los hechos y lo puede demostrar con documentos sacados del archivo municipal, como la de la asociación que no desea, pero sí el
15

El artículo séptimo del Convenio de Faro se compromete expresamente con el diálogo, pero son declaraciones de principios que deben ser operativizados en la práctica cotidiana de la gestión del patrimonio cultural. 
En la isla de Tenerife la metodología del World Café se ha venido aplicando en ámbitos como la convivencia intercultural (estrategia Juntos en la misma dirección) o el desarrollo comunitario y el empleo (proyecto Barrios por el empleo: juntos más fuertes). Es colaborando con estas iniciativas promovidas por el Cabildo de Tenerife como nos hemos familiarizado con una metodología que estamos trasladando a la gestión del patrimonio cultural.

17

Para profundizar en la amplia variedad de metodologías participativas centradas en el diálogo recomendamos la obra Trazando el diálogo. Herramientas esenciales para el cambio social (Bojer et ál. 2012).
Ayuntamiento, la "fosilización" que creen que supondrá el título de BIC para celebrar los cincuenta años de la tradición, como la del párroco que rehúsa el interés turístico para su iglesia porque en ella no hay tesoros que valga la pena enseñar (se esfumaron con la desamortización), como la del técnico municipal que tampoco ve indicios de patrimonio en una tipología de vivienda que no tendrá más de sesenta años pero que el consultor externo contratado afirma que sí los hay, como la del colectivo de jóvenes que quiere innovar una laboriosa y poco lucrativa artesanía para que no tenga que sucumbir junto con sus últimas exponentes vivas, o como la del político que dice que las tradiciones no se tocan porque eso siempre ha sido así, y el respeto por las tradiciones además va en el programa político.

El giro democratizador o participativo de la UNESCO a raíz de la Convención para la Salvaguardia del Patrimonio Cultural Inmaterial (obrado, en cualquier caso, por otras muchas organizaciones de la sociedad actual), que da voz, visibilidad y legitimidad a los colectivos minorizados en los procesos de patrimonialización quebrando las tradicionales jerarquías (Quintero Morón y Sánchez-Carretero 2017, 54), nos habilita al uso de una aproximación epistemológica, teórica y metodológica centrada en el diálogo como forma de construir conocimiento $\mathrm{y}$, sobre todo, para actuar en torno al patrimonio, como decidir, por ejemplo, qué patrimonio queremos que nos represente y qué valores queremos atribuirle. Al poner en el centro de la planificación local del patrimonio a las personas, a las comunidades, a sus habilidades comunicativas, a sus competencias culturales, conocimientos, saberes y experiencias, etc., el discurso patrimonial autorizado vendría a ser, entonces, un discurso más entre todos los intervinientes en la gestión del patrimonio cultural. El vecino, en definitiva, deja de ser objeto (de investigación) para convertirse en sujeto (de transformación).

\section{UN CAFÉ POR EL PATRIMONIO}

Metodologías centradas en el diálogo hay muchas, y las podemos usar para distintos tipos de objetivos, procesos y fases, siendo una de sus virtudes la flexibilidad y la creatividad que nos permiten liberar. Podemos citar, como ejemplos, el método European Awareness Sustainability Workshop (EASW), el Open Space Technology, la Indagación Apreciativa, el Proyecto Conversaciones Públicas, el Teatro del Oprimido, el Grupo Nominal, los Grupos de Creación Participativa, el Método de la Construcción del Consenso (MCC), etc. Nosotros hemos empleado en los tres municipios la metodología del World Café para la elaboración de iniciativas que han girado siempre en torno a una gran cuestión: "¿Qué queremos hacer con nuestro patrimonio?" ( $Y$ el qué admite el cómo). Hemos elegido esta metodología ${ }^{16}$ porque crea un entorno especialmente favorecedor para que se produzca el diálogo ${ }^{17}$ y emerja la creatividad y el conocimiento colectivo en un contexto acogedor de 

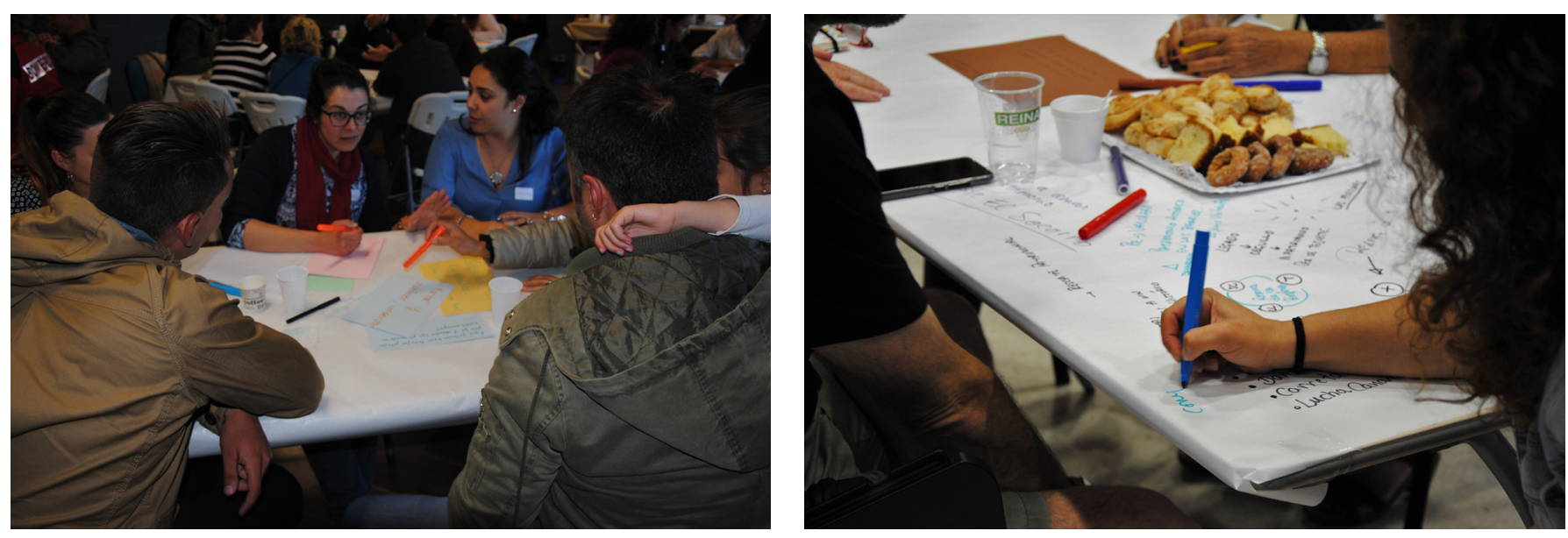

A la izquierda, taller participativo para la protección y la puesta en valor de la cultura del almendro de

igualdad y confianza entre los y las participantes. El World Café es un proceso ideado por los consultores Juanita Brown, David Isaacs y The World Café Community (2005) para conversar sobre cosas que nos importan y generar ideas que abran vías innovadoras de acción, potenciando la capacidad comunicativa y dialógica inherente a las personas y el conocimiento que solo puede hallarse en lo colectivo, es decir, cuando nos reunimos para pensar y actuar juntos.

Las vibrantes e inspiradoras tertulias que todos y todas habremos tenido alguna vez alrededor de una mesa de cafetería las llevamos, durante el proceso de planificación, al centro ciudadano, al centro de interpretación, o a la sala de exposiciones, que harán las veces de improvisada "cafetería comunitaria". Los tablones, los escritorios o las mesas que allí encontremos los convertimos en agradables mesas de cafetería, y el papel Kraft que normalmente usamos para hacer talleres, en impolutos manteles. Al bar de la esquina le podemos encargar, entre otras cosas, unos termos de café, agua, zumos y un picoteo, y con un ordenador portátil y unos altavoces pondremos incluso algo de música de fondo. En cada mesa se sentarán aproximadamente cuatro, cinco o seis invitados, más un anfitrión (alguien del equipo técnico) que tendrá como único propósito facilitar el diálogo. Colocaremos tantas mesas como sean necesarias en función del número de asistentes, así como folios, marcadores y rotuladores de colores que las personas usarán en los manteles como apoyo durante las conversaciones.

A nuestra cafetería no invitamos solamente a vecinos y colectivos ciudadanos y culturales, sino también a técnicos municipales, a concejales, a especialistas, y a cualquier persona ${ }^{18}$ u organización que pueda y quiera aportar ideas sobre "algo relacionado con el patrimonio", pues durante la convocatoria no desvelaremos todavía el tema específico de conversación, procurando así despertar la curiosidad, aunque insistiremos en que será una reunión

18

Y ello incluye, al menos, la dimensión intergeneracional, y como objetivo que nos marcamos para el futuro, también la intercultural. En la sesión de World Café realizada en Santiago del Teide, niños y niñas de entre 8 y 16 años participaron en la conversación junto con los adultos, habiendo valorado, entre otras muchas cosas, que eran los herederos y herederas de una cultura del almendro en peligro extinción. 
19

La asistencia al World Café, y por consiguiente la diversidad de puntos de vista y la creatividad que pueda llegar a generarse durante la actividad, estará condicionada por la labor previa de relaciones sociales que hayamos llevado a cabo durante las etapas iniciales del proceso de planificación (entrevistas, sociogramas, diagnósticos, etc.). Tal es así, que la asistencia o no a los talleres suele escenificar las alianzas y los conflictos presentes en la comunidad. La combinación de las técnicas participativas con otras como la entrevista individual permite no dejar fuera actores que por diversas razones rehúsan a acudir a los encuentros colectivos de planificación.

Taller participativo para el Inventario del Patrimonio Cultural Inmaterial Marítimo-Pesquero de la Reserva de la Biosfera de Anaga (Punta del Hidalgo, Tenerife, 2019) amena y no un debate, una asamblea, o un grupo de discusión. Al llegar, los invitados -que suelen mostrar un semblante que oscila entre la curiosidad y la extrañeza- irán tomando asiento en alguna de las mesas según les plazca (probablemente lo harán por afinidad) e irán sirviéndose un café al tiempo que interactúan entre ellos y con el equipo técnico. Pero no permanecerán siempre en la misma mesa, con las mismas personas y en la misma conversación (el anfitrión sí que lo hará), sino que se irán desplazando varias veces (dos o tres, por ejemplo, y que llamamos turnos de conversación) a otras mesas y con personas distintas para seguir reflexionando sobre la misma cuestión u otra que se les proponga.

La interacción que se obtiene con el movimiento es lo que da significación a esta metodología, y es de esta manera, a través del encadenamiento de diálogos, "conectando" todos los sectores de la comunidad con algún tipo de interés en el patrimonio cultural local, como se produce la "espontánea polinización cruzada de relaciones, ideas y significados" (Hurley y Brown 2009), emergiendo la inteligencia colectiva y la oportunidad de innovación, y que en el plan de gestión podremos plasmar en los ejes de actuación. Los anfitriones, además de explicar el funcionamiento del World Café, de descubrir las preguntas (escritas en tarjetas) y de facilitar el diálogo, en cada turno resumirán lo anteriormente conversado a los nuevos invitados.

Si la convocatoria ${ }^{19}$ y el movimiento son importantes, la pregunta o tema clave a tratar lo es en igual medida. Cuando en las tertulias de café con amigos, familiares o compañeros de trabajo acabamos concluyendo tras una apasionante charla que "¡hemos arreglado el mundo en media hora!”, quizá

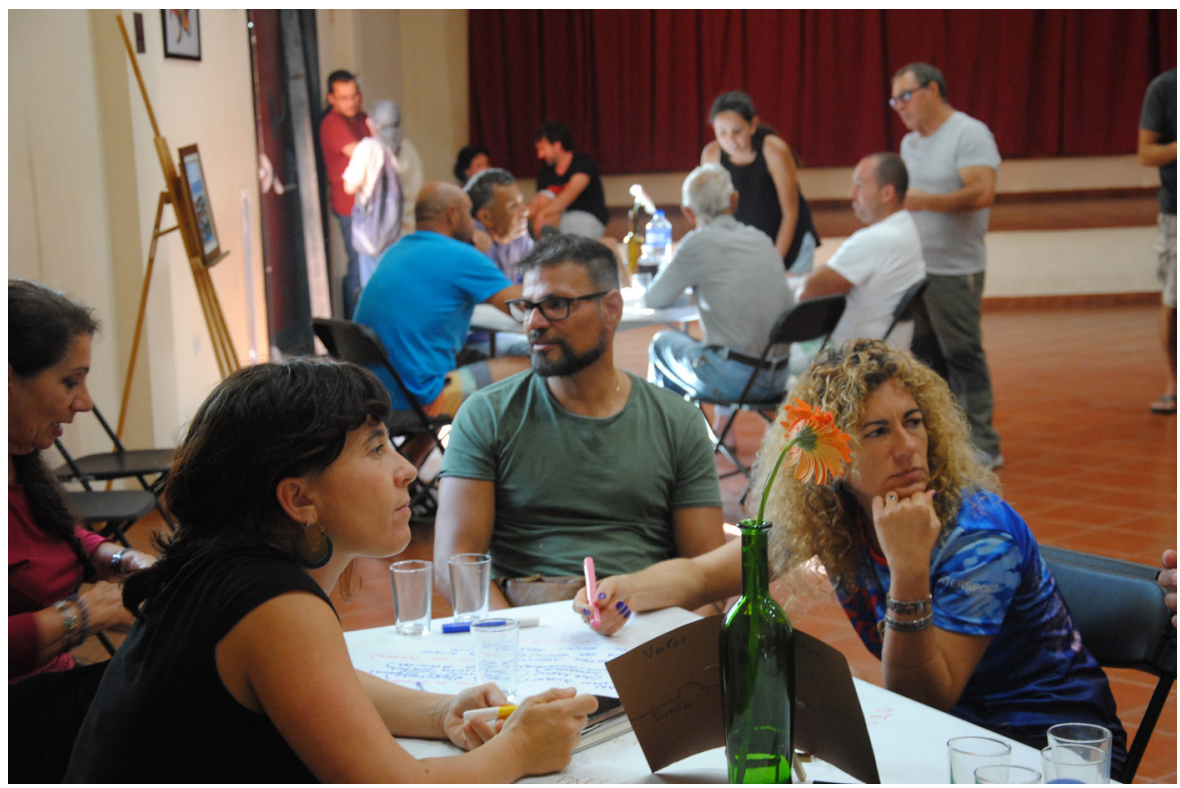




\section{Candelaria}

Tres rondas de conversación de quince minutos con una única pregunta: ¿Cómo podemos conservar y dinamizar nuestro patrimonio?

\section{Santiago del Teide}

Cuatro rondas de conversación con dos preguntas consecutivas. Primera y segunda ronda: ¿Qué representa el almendro para nuestro municipio? (diez minutos por ronda)

Tercera y cuarta ronda: ¿Qué podemos hacer todos/as juntos/as para que el almendro siga floreciendo en nuestro municipio? (quince minutos por ronda)

no estemos demasiado lejos de cómo funciona un café comunitario ${ }^{20}$. La pregunta clave va de eso, de intentar arreglar, si no el mundo, al menos sí una muy pequeña parcela que pueda estar de nuestra mano, para lo cual debemos hacernos buenas preguntas, que sean significativas, que inviten a la reflexión y a la creatividad, que remitan a nuestros valores, que conduzcan a formular nuevas preguntas, y que siendo comprensibles, incluso simples, también respondan a los objetivos de la planificación (Vogt, Brown y laacs 2003). Hacer preguntas estratégicas significa alejarse de los problemas y de posiciones defensivas y aproximarse a las posibilidades que propicien la transformación que persigue el proceso de planificación, pues para los problemas ya están el diagnóstico y técnicas como el DAFO. Podemos hacer una o varias preguntas durante una única sesión de World Café, las cuales han sido pensadas previamente por el equipo técnico. De hecho, llegar a las preguntas que consideramos más poderosas según cada proceso puede llevar unos días de reflexión, y, aun así, nunca estaremos seguros del todo de que hayan sido las más idóneas. Siempre puede haber una pregunta mejor, y con la experiencia que adquirimos con cada World Café mejoramos "el arte de hacer preguntas".

Durante dos o tres horas, en una única o sucesivas sesiones de World Café, las personas han conectado con otras personas (vecinos con políticos, especialistas con colectivos culturales, etc.), todos y todas han escuchado y han sido escuchados, todos y todas han podido intercambiar conocimientos, saberes, emociones y experiencias, y, sobre todo, habrán descubierto conjuntamente ideas, recursos y estrategias desde la pluralidad de perspectivas sobre el patrimonio cultural. Puede incluso haberse producido, cuando menos, un empoderamiento individual en las personas participantes, traducido, en términos de Zimmerman, en el desarrollo de la conciencia crítica y del comportamiento participativo $(2000,47)$.

Al finalizar todas las rondas de conversación que hayamos establecido, cada mesa consensuará las ideas que considere más interesantes. Luego, se compartirán con todo el grupo en plenario, para lo cual será útil escribirlas en tarjetas que colocaremos en una pared, una pizarra, un tablón, o lo que tengamos

\section{Tegueste}

Tres rondas de conversación de quince minutos con una única pregunta: ¿De qué manera nuestro patrimonio cultural puede contribuir a mejorar el municipio?

Preguntas planteadas en los tres procesos de planificación

20

A la hora de realizar la convocatoria, hay que sopesar la propia terminología. En nuestras conversaciones hemos preferido castellanizar la denominación World Café para que fuera más comprensible y accesible, sustituyendo la palabra World por la de comunidad 

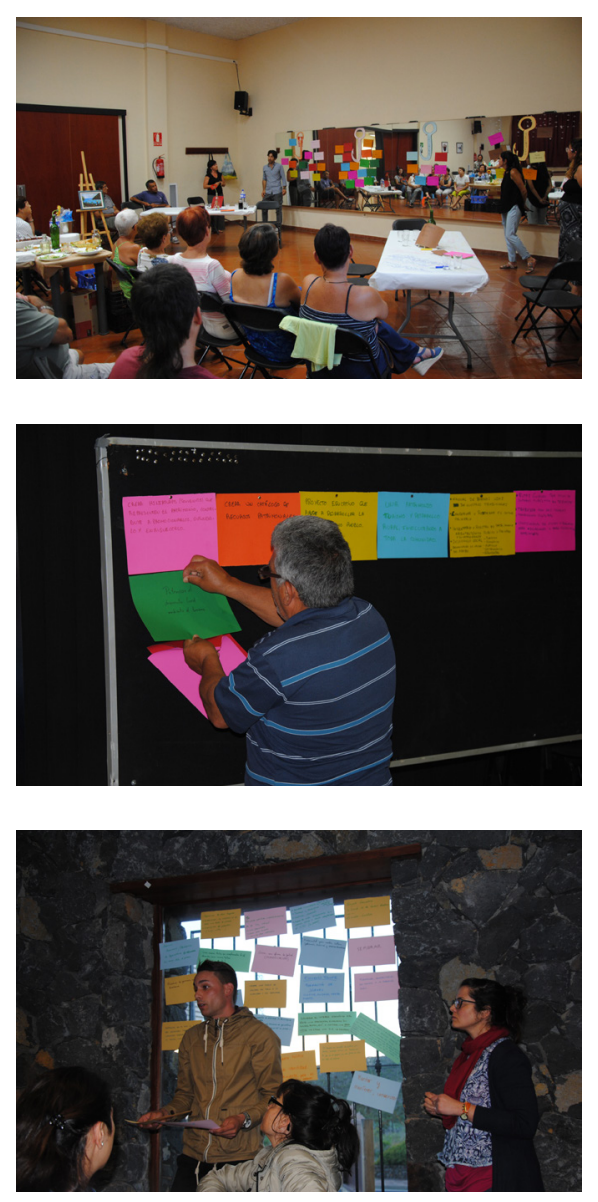

Puesta en común de las ideas surgidas durante los talleres participativos: para el Inventario del Patrimonio Cultural Inmaterial Marítimo-Pesquero de la Reserva de la Biosfera de Anaga (Punta del Hidalgo, Tenerife, 2019), para la elaboración del Diagnóstico y plan de gestión del patrimonio cultural de Tegueste (2018) y para la protección y la puesta en valor de la cultura del almendro de Santiago del Teide (2018) (de arriba a abajo) a mano, como una ventana. Muchas ideas tan interesantes como las elegidas no se perderán, pues habrán quedado registradas en los manteles para su posterior análisis e incorporación al plan de gestión. Las iniciativas finales suelen fluctuar entre lo concreto (poner en valor un determinado bien cultural, hacer un inventario patrimonial, etc.) y lo estratégico (crear un área específica de patrimonio, "contar con la comunidad", hacer un plan de acción, etc.).

La del World Café quizá no sea una metodología ideal para planificaciones que esperan alcanzar certezas, sino reflexivas, posibilistas y creativas, y en las que es igual de importante el camino que se recorre para obtener dichos resultados por cuanto genera, entre otros muchos aspectos, sensibilización y acción en torno a la gestión pública del patrimonio cultural local. Acostumbramos, de hecho, a estar tensionados entre la planificación rigurosa que se traduzca a ejes, acciones y cronogramas, y la indeterminación de los escenarios posibles, no pudiendo prometer soluciones definitivas sino opciones que se despliegan y que deben ser exploradas si a las comunidades se les brinda el tiempo y los recursos necesarios. Estos planes actualmente están sobre las mesas (o en los cajones) de los gestores políticos y técnicos, y desconocemos si se darán pasos hacia una gobernanza participativa sostenida en el tiempo que supere los niveles de participación más elementales.

\section{EL DIÁLOGO “A DEBATE”}

Las metodologías participativas, aplicadas con el dejar hacer de la administración municipal, y del mismo modo que otros espacios para la participación ciudadana (mesas vecinales, consejos, presupuestos participativos, consultas populares, etc.), podrían verse como procesos de repersonalización impulsados por las instituciones públicas modernas (Velasco et ál. 2006), al estilo, por ejemplo, de lo que hace en el ámbito privado una sucursal bancaria al eliminar las ventanillas y los mostradores para ofrecernos una sensación de proximidad, aunque el interés instrumental continúe inmutable. Visto así, las mesas, los manteles y los cafés de nuestra cafetería formarían parte de una "puesta en escena", y el diálogo, el consenso, la visión común que emana de la colaboración, un discurso retórico, pues en realidad las decisiones ya han sido tomadas "racionalmente" o se tomarán sin el concurso ciudadano. Este doble código de vinculación, el instrumental, que nos observa como sujetos pasivos, y, junto a él, el dejar opinar y decidir, que lo hace como sujeto activo (Velasco et ál. 2006, 333), es un proceso operado por las instituciones modernas con el que tenemos que contar en la planificación participativa del patrimonio cultural. Tal proceso de desvinculación (moderna) y revinculación (tardomoderna) de la ciudadanía en la gestión de lo público no ha escapado a la reflexión crítica de las propias comunidades locales con las que hemos elaborado los diagnósticos: 
"Participación ciudadana era los vecinos que cada uno barría el frente de su casa. Eso se ha hecho toda la vida. Participación ciudadana era que en la fiesta todo el mundo trabajaba. Tú terminabas la jornada de trabajo y venías a las seis o siete de la tarde, o a la hora que fuera, a abrir huecos. Yo me acuerdo de pibe venir a abrir los huecos para poner los palos de las banderas, y eso lo hacían los vecinos. Los ayuntamientos han cometido un grave error, la administración local, que es el querer acaparar todo, controlar todo. ¿Las banderas? Que las ponga el ayuntamiento. ¿Las luces? Que las ponga el ayuntamiento. ¿Los papelillos? A veces el ayuntamiento los pone. Recuperar ahora... como dicen... Ahora es empoderar a los ciudadanos. Entonces, ¿para qué les quitaste el poder?, ¿para qué les quitaste el poder?" (vecino).

En este artículo hemos tratado de mostrar la utilidad de una herramienta metodológica basada en el diálogo estructurado para la planificación participativa del patrimonio cultural local, siempre que a este lo concibamos como un campo dinámico en continua transformación, es decir, como un proceso cultural en el que el conflicto es una parte consustancial del mismo (Smith 2011) que no debemos negar ni intentar sortear, sino procurar integrar en la planificación. Apelamos, entonces, al ya extendido axioma presente en las actuales teorías sobre el conflicto, que observarían a este último no como una situación problemática, sino como una oportunidad para el cambio ${ }^{21}$; una oportunidad para sentar en la misma mesa de diálogo a todas las partes y a todos los puntos de vista en un espacio de comunicación horizontal, de confianza, tolerancia e igualdad. Hacerlo de este modo puede contribuir a fortalecer o tejer relaciones en la comunidad, a favorecer la participación, la creatividad y la innovación, a propiciar la reflexión colectiva y la consecución de una visión común compartida en relación a qué es o en qué consiste nuestro patrimonio y cómo nos gustaría gestionarlo, y ello en beneficio del patrimonio local y, sobre todo, de las condiciones de vida de las personas que lo definen, le dan vida, lo significan, o lo salvaguardan, que vendrían a ser los genuinos protagonistas de cualquier proyecto patrimonial.

Aún a pesar de los escasos recursos destinados al patrimonio cultural, del recelo y la incomprensión del enfoque participativo por parte de los gestores públicos, del tokenismo imperante en las administraciones públicas en cuanto a la gestión del patrimonio, de las propias limitaciones de la aplicación de la metodología participativa, del todavía pujante discurso autorizado que restringe el acceso de la comunidad a una fuente de sentido que le es propia, y así un largo etcétera, creemos que es necesario insistir en la línea de actuación propuesta en estas páginas si de lo que se trata es de "salvaguardar" no un singular patrimonio, sino a las comunidades sin las cuales aquel no tendría razón de ser.

\section{1}

Lederach, por ejemplo, define el conflicto "como un motor de cambio que mantiene las relaciones y las estructuras sociales vivas, sinceras y dinámicamente sensibles a las necesidades, las aspiraciones y el crecimiento humanos" (Lederach 2010, 31). 


\section{BIBLIOGRAFÍA}

- Aguilar, M.J. y Buraschi, D. (2017) Claves dialógicas para una educación intercultural crítico-transformadora. Interaçoes, n. ${ }^{\circ}$ 43, pp. 233-253

- Ariño, A. (2007) La invención del patrimonio cultural y la sociedad del riesgo. En: Rodríguez Morató, A. (ed.) La sociedad de la cultura. Barcelona: Ariel, pp. 71-88

- Arnstein, S.R. (1969) A ladder of citizen participation. Journal of the American Institute of Planners, vol. $35, n .^{\circ} 4$ pp. 216-224

- Aubert, A., Flecha, A., García, C., Flecha, R. y Racionero, S. (2013) Aprendizaje dialógico en la Sociedad de la Información. Barcelona: Hipatia

- Beck, U., Giddens, A. y Lash, S. (1997) Modernización reflexiva. Política, tradición y estética en el orden social moderno. Madrid: Alianza

- Bojer, M.M., Roehl, H., Knuth, M. y Magner, C. (2012) Trazando el diálogo. Herramientas esenciales para el cambio social. Bilbao: Fundación Gizagune

- Brown, J., Isaacs, D. y The World Café Community (2005) The world café: shaping our futures through conversations that matter. San Francisco, CA: Berrett-Koehler Publishers

- Consejo de Europa (2005) Convenio Marco de Consejo de Europa sobre el valor del patrimonio cultural para la sociedad. Faro, 27.X.2005, Serie de Tratados del Consejo de Europa n. ${ }^{\circ}$ 199. Disponible en: https://rm.coe. int/16806a18d3 [Consulta: 14/10/2020]

- ConsejodeEuropa(2014)ConclusionesdelConsejosobre la gobernanza participativa del patrimonio cultural. Diario Oficial de la Unión Europea, C 463/1, 23 de diciembre de 2014. Disponible en: https://eur-lex.europa.eu/legal-content/ ES/TXT/PDF/?uri=CELEX:52014XG1223(01)\&from=EN [Consulta: 16/11/2020]

- Galván, J.A. (2002) La construcción de la identidad cultural en regiones insulares: el caso de las Islas Canarias. En: García, J. L. (ed.) Identidad y desarrollo local. Perspectivas de la globalización desde las Islas Canarias. Santa Cruz de La Palma: Cabildo Insular de La Palma, pp. 171-194

- Garrido García, F.J. (2001) El análisis de redes en el desarrollo local. En: Villasante, T.R., Montañés, M. y Martín, P. (coord.) Prácticas locales de creatividad social. Construyendo ciudadanía 2. Barcelona: El Viejo Topo, pp. 49-63

- Giddens, A. (2015) Consecuencias de la modernidad. Madrid: Alianza

- Godenau, D. y Suárez Sosa, S.J. (2006) El abandono agrario en Tenerife. Mundo rural de Tenerife, n. ${ }^{\circ}$ 5, pp. 16-17

- González Alcantud, J.A. (2003) Patrimonio y pluralidad. El largo camino conjuntivo de la alteridad y la materialidad cultural. En: González Alcantud, J. A. (ed.) Patrimonio y pluralidad. Nuevas direcciones en Antropología patrimonial. Granada: Biblioteca de Etnología. Diputación de Granada, pp. $13-40$

- Hernández-Ramírez, J. y Quintero Morón, V. (2019) L'efecte UNESCO. Gestió turística o gestió patrimonial dels Patis de Còrdova? Revista d'Etnologia de Catalunya, n. ${ }^{\circ}$ 44, pp. 76-93

- Hurley, T.J. y Brown, J. (2009) Liderazgo conversacional: pensando juntos para el cambio. Systems Thinker, vol. 20, n. ${ }^{\circ} 9$

- Lederach, J.P. (2010) Transformació de conflictes. Petit manual d'ús. Barcelona: Icària

- Ley 10/2015, de 26 de mayo, para la salvaguardia del Patrimonio Cultural Inmaterial. Boletín Oficial del Estado, n. ${ }^{\circ} 126$, de 27 de mayo de 2015. Disponible en: https://www. boe.es/buscar/doc. php?id=BOE-A-2015-5794 [Consulta: 16/11/2020]

- Marchioni, M. (1999) Comunidad, participación y desarrollo. Teoría y metodología de la intervención comunitaria. Madrid: Editorial Popular

- Martín Gutiérrez, P. y Villasante, T.R. (2007) Redes y conjuntos de acción: para aplicaciones estratégicas en los tiempos de la complejidad social. Política y Sociedad, vol. 44, n. $^{\circ} 1$, pp. $125-140$

- Ministerio de Educación, Cultura y Deporte (2015) Plan Nacional de Salvaguarda del Patrimonio Cultural Inmaterial. Primera edición 2011. Madrid: Secretaría General Técnica, Subdirección General de Documentación y Publicaciones. Disponible en: http://www.culturaydeporte. gob.es/planes-nacionales/dam/jcr:74b2f235-d9c0-41e0b85a-0ed06c5429da/08-maquetado-patrimonio-inmaterial. pdf [Consulta: 4/2/2021]

- Quintero Morón, V. y Sánchez-Carretero, C. (2017) Los verbos de la participación social y sus conjugaciones: contradicciones de un patrimonio "democratizador". Revista andaluza de Antropología, n. ${ }^{\circ} 12$, pp. 48-69

- Sánchez-Carretero, C. (2012) Hacia una antropología del conflicto aplicada al patrimonio. En: Santamarina, B. (ed.) Geopolíticas patrimoniales: De culturas, naturalezas e inmaterialidades. Una mirada etnográfica. Valencia: Germania, pp. 195-210

- Sani, M. (2016) La gobernanza participativa del patrimonio cultural. En: Observatorio Social de "la Caixa". Artículos. Septiembre. Disponible en: https:// observatoriosociallacaixa.org/-/la-gobernanzaparticipativa-del-patrimonio-cultural [Consulta: 26/03/2020]

- Sclavi, M. (2010) II metodo del confronto creativo: un upgrading della democracia. Riflessioni sistemiche, n. ${ }^{\circ} 2$, pp. $128-138$ 
- Simon, N. (2010) The participatory museum. Santa Cruz (California): Museum 2.0.

- Smith, L. (2011) El espejo patrimonial. ¿llusión narcisista o reflexiones múltiples? Antípoda. Revista de Antropología y Arqueología, n. ${ }^{\circ}$ 12, pp. 39-63

- UNESCO (2003) Convención para la salvaguardia del patrimonio cultural inmaterial [Instrumento de ratificación de la Convención para la salvaguardia del Patrimonio cultural inmaterial, hecho en París el 3 de noviembre de 2003]. Boletín Oficial del Estado, n. ${ }^{\circ} 31$, de 5 de febrero de 2007, pp. 5242-5248. Disponible en: https://www.boe.es/buscar/ doc.php?id=BOE-A-2007-2382 [Consulta: 14/07/2020]

- UNESCO (2014) Manual de referencia. Gestión del Patrimonio Mundial Cultural. París: UNESCO

- Velasco, H., Díaz De Rada, Á., Cruces, F., Fernández, R., Jiménez De Madariaga, C. y Sánchez, R. (2006) La sonrisa de la institución. Confianza y riesgo en sistemas expertos. Madrid: Editorial universitaria Ramón Areces

- Vogt, E., Brown, J. y Isaacs, D. (2003) The Art of Powerful Questions. Catalyzing Insight, Innovation, and Action. Waltham, Mass: Pegasus Communications

- Zimmerman, P. (2000) Empowerment Theory: Psychological, Organizational and Community Levels of Analysis. En: Rappaport, J. y Seidman, E. (eds.) Handbook of Community Psychology. Nueva York: Kluwer Academic Plenum, pp. 43-64 